\section{Reduce uncertainty in UK badger culling}

The UK government's plans to license badger culling for the control of tuberculosis (TB) in cattle are controversial; by contrast, the Welsh Assembly has decided to vaccinate rather than cull badgers.

Extensive badger culls may reduce cattle TB (C. A. Donnelly et al. Nature 439, 843-846; 2006), but complex disease dynamics mean that killing too few animals can actually increase it (C. A. Donnelly et al. Nature 426, 834-837; 2003). However, culling too many badgers risks local extinction, contravening the Bern Convention on the Conservation of European Wildlife and Natural Habitats. Natural England, the agency monitoring the cull, will therefore be required to set minimum and maximum cull numbers for each licence. But the effects are difficult to predict.

Targets for licences will draw on regional estimates of badger abundance, but badger densities are uncertain, owing to their secretive behaviour. Surveys of TB-affected areas in Gloucestershire, where one of two pilot culls is planned, indicate a mean density of 3.3 badgers per square kilometre, with a $95 \%$ confidence interval of 2.4-4.6 and substantial local variation (D. Parrott et al. Eur. J. Wildl. Res. 58, 23-33; 2012).

As well as measurement uncertainty, there will be random (Poisson) variation about mean densities, and binomial variation around mean capture probabilities. These three sources of uncertainty together mean that licensed culling of 344 badgers intended to represent $70 \%$ of badgers within a $150-\mathrm{km}^{2}$ area - could remove anywhere between $51 \%$ of the resident badger population (risking an increase in cattle TB) and 100\% (risking a breach of the Bern Convention).
This uncertainty cannot be eliminated, but could be reduced by detailed badger surveys before and after each cull. This would increase culling costs, which are already projected to exceed the financial benefits for farmers. Christl A. Donnelly $M R C$ Centre for Outbreak Analysis and Modelling, Imperial College London, London, UK. c.donnelly@imperial.ac.uk Rosie Woodroffe Institute of Zoology, Regent's Park, London, UK. Competing financial interests declared; see go.nature.com/3q9olb.

\section{Personalized drugs should cut care costs}

Spending on health care is becoming unsustainable in developed countries because of ageing populations, changing disease patterns and increasing patient expectations. To control costs, governments and funding organizations should be helping to steer the revolution in personalized medicine.

Protein-based biological drugs ('biologics'), for example, are expected to account for seven of the world's ten best-selling drugs by 2016 , but they are hugely expensive. Anticancer biologics can cost up to US\$100,000 per patient per year, even though they might extend life by just a few months.

Personalized medicine will ensure that such drugs are prescribed only to those patients who stand to benefit. These patients can be identified using molecular biomarkers to determine the genetic profiles of their diseases. Health-care funders should demand that companion biomarker tests become the norm for biologics and other expensive drugs, and should provide incentives for drug firms as necessary.

A pathway for approving cheaper, generic versions of biologics has now been established in the United States and the European Union. However, the need for detailed assessment of the clinical efficacy and safety of these drugs remains a major hurdle to their commercialization. Therefore, funders of health care may have to continue paying premium prices even once a biologic has lost exclusivity, making their personalized prescription all the more critical.

Nafees N. Malik Institute of Biotechnology, University of Cambridge, Cambridge, UK. nafees_malik@hotmail.com

\section{Include all institutes in publishing index}

The Global Top 100 ranking in the Nature Publishing Index (www.natureasia.com/en/ publishing-index/global) does an injustice to transnational institutions by not taking into account all contributions when listing their publication output.

For example, you rank Germany's Max Planck Institutes in third position. But the Max Planck Institutes in the Netherlands, the United States and Italy are full members of the same research organization. Including these would push the Max Planck Institutes up in your rankings (our institute in the Netherlands, for instance, would have added three Nature papers to your 2011 tally).

Stephen Levinson on behalf of 7 co-authors ${ }^{*}$, Max Planck Institute for Psycholinguistics, Nijmegen, the Netherlands.

stephen.levinson@mpi.nl

${ }^{*}$ See go.nature.com/zrcfru for a full list.

Editorial note: The Global Top 100 rankings in the Nature Publishing Index represent only a preliminary listing (see go.nature.com/gwdeau), with constituent bodies of transnational scientific research organizations subdivided by country of location to allow easy comparison within nations. Future indexes will take these and other complex issues into account.

\section{Food safety body is bound to draw fire}

You draw attention to accusations of industry ties at the European Food Safety Authority (EFSA) and the role these have in public and political debates (Nature 485, 279-280 and 294-295; 2012). Yet the independent nature of this agency means that it will always draw fire.

The agency was formed in the wake of the late-1990s BSE crisis to restore public trust and consumer confidence in nutrition, food science and politics in Europe. Paradoxically, its creation has led to a proliferation of interest groups and has strengthened ties between academia and industry, further politicizing science.

Through its evaluations of health claims on food products, EFSA's mandate demands judgement, thereby inviting scrutiny, critique and protest from all sides. Examples include criticism from gut-health scientists for EFSA's rejection of claims about pro- and prebiotics, and from non-governmental organizations for its acceptance of genetically modified crops. This makes any meaningful separation between science and politics impossible.

Forced to make decisions, EFSA is bound to be constantly criticized, just as politicians are. Kim Hendrickx University of Liège, Belgium, and Maastricht University, the Netherlands. khendrickx@ulg.ac.be

Bart Penders Maastricht University, the Netherlands.

CONTRIBUTIONS Correspondence may be sent to correspondence@ nature.com after consulting the author guidelines at http://go.nature.com/ cmchno. Alternatively, readers may comment online on anything published in Nature: www.nature.com/nature. 